\title{
PERCEIVED USABILITY OF LEARNING MANAGEMENT SYSTEMS AND UNIVERSITY WEBSITES: A SYSTEMATIC REVIEW
}

\author{
Prokopia Vlachogianni ${ }^{1}$, Nikolaos Tselios ${ }^{1}$ and Michalis Xenos ${ }^{2}$ \\ ${ }^{I}$ Department of Educational Sciences and Early Childhood Education \\ ${ }^{2}$ Computer Engineering and Informatics Department \\ University of Patras, 26500 Patras, Rio, Greece
}

\begin{abstract}
This paper presents the findings of a systematic meta-analysis of perceived usability evaluation studies of Learning Management Systems (LMS) and University Websites used in the context of higher education. The research was conducted after studying, organizing, and analyzing the results of 33 research papers, which report evaluation of the perceived usability of LMS and websites using the System Usability Scale (SUS). The results obtained were organized and analyzed according to the following: (a) the usability score obtained by the SUS questionnaire, (b) the type of educational technology used (LMS or University website), (c) the type of participant (student or teacher), (d) the age and (e) the number of participants in each study. Statistical analysis demonstrated a satisfactory level of perceived usability both for LMS and for University Websites respectively. Moreover, participants' age was found to be significantly associated with SUS score as well as the number of participants in the LMS context. However, as far as university websites are concerned, the number of participants does not seem to be related with SUS score. In addition, no significant difference was derived in the LMS context between SUS score and the type of participant (student - teacher). Finally, there was no significant improvement of the perceived usability over time both for the Learning Management Systems and for the University Websites. The reported findings will provide useful benchmarks for teachers and educational technology designers.
\end{abstract}

\section{KEYWORDS}

System Usability Scale, Learning Management Systems, University Websites, Higher Education, Review, Meta-Analysis

\section{INTRODUCTION}

During the recent years, educational technology has been widely adopted in every aspect of the educational process. In particular, in higher education it seems that various forms of educational technology are widely used. As a consequence, significant opportunities are provided for the improvement of quality and accessibility of university teaching while at the same time reducing some costs (McCann et al., 1998). An important aspect, when it comes to technology, is its perceived usability. In an educational setting, students' learning experience and, in turn, academic performance is greatly affected by the usability of educational technology systems provided by an institution. A user interface which meets users' needs in an intuitive way will lead to more frequent use and increased adoption. On the contrary, it will require more time to learn how to operate it at the expense of focusing on the actual learning content (Ardito et al., 2006).

The main goal of the research reported in this paper was to provide a standardized frame of reference to all stakeholders regarding usability in educational technology used in the context of higher education; specifically, for Learning Management Systems (LMS) and university websites. In specific, usability levels of the abovementioned systems are examined and compared with the criteria set by Bangor et al. (2009). In addition, all existing information individual researches provided are summarized in an unbiased, systematic way so to extract more compact conclusions about usability in higher education. Furthermore, a quantitative analysis followed up in order to investigate possible correlations among variables.

LMS allow asynchronous and synchronous communication, delivery of learning content, assessment and class management (Coates et al., 2005). A rather overlooked form of educational technology used in higher education is university websites. University websites are key components for institutions because they are cost 
and time efficient and communicate the university's vision, goals, values and culture to various stakeholders (students, alumni, prospective students, parents, faculty, staff, Mentes \& Turan, 2012). In this context, it should meet in the same time all stakeholders' needs. A usable university website should be considered as an asset and a competitive advantage for attracting prospective students. According to Smith and Oliver (2000) the adoption of technologies that provide flexibility, access and convenience will be the cornerstone to institutions' continued viability in the frame of the competitiveness of the world market.

In this systematic review, perceived usability of two categories of educational technology systems used in higher education, namely Learning Management Systems (LMS) and University Websites was examined. The results of 33 research papers are organized and analyzed evaluating the perceived usability using the System Usability Scale (SUS).

SUS is a questionnaire which is used for evaluating perceived usability. It is well received as a highly valid and reliable tool (Orfanou et al., 2015) and is the most widely adopted questionnaire for perceived usability evaluation of software and products (Tullis \& Albert, 2008). However, there is no universal consensus, as it is reflected upon the number of questionnaires used for usability evaluation of products and/or software currently (Brooke, 1996; Lewis 1991, 1992, 1995; Tullis \& Albert, 2008). Surprisingly, usage of questionnaires for the evaluation of the perceived usability of educational software is quite limited as it is demonstrated to the research data. Only in recent years SUS has begun to be used for ICT's usability evaluation in Education (Orfanou et al., 2015). It is therefore reasonable to have an overview of these studies in order to investigate the levels at which LMS and university websites score and to identify the frequency SUS scale is used.

The available research data regarding the relation of gender with SUS score seem quite contradictory. On the one hand, in a dataset of 213 surveys Bangor et al. (2008) found no significant difference between the mean SUS scores obtained from females $(\mathrm{M}=71.6)$ and males $(\mathrm{M}=70.2, \mathrm{p}=0.586$, $\mathrm{ns})$. Ituma (2011) evaluating the perceived usability of Blackboard WebCT came into the same conclusion. Orfanou et al. (2015) also found no significant difference in SUS score between women (mean=76.30, $\mathrm{SD}=13.16)$ and men $(\mathrm{M}=76.21, \mathrm{SD}=13.40)$. Similar results were provided by Georgsson and Staggers (2015) who found that males rated higher than females a diabetes mHealth system (males, $\mathrm{M}=83.13, \mathrm{SD}=2.39$, females, $\mathrm{M}=79.69, \mathrm{SD}=14.98$ ).

Concerning age, the research data obtained are also not conclusive. Granić and Ćukušić (2011) found a significant negative correlation between SUS score and age $(\mathrm{r}=-0.467, \mathrm{p}=0.001, \mathrm{~s})$; thus younger participants tend to assign a higher SUS rating than the older ones. In a sample of 213 participants Bangor et al. (2008) found that younger participants tend to give higher SUS scores too $(r=-0.203, p=0.03, s)$. Binyamin et al. (2016) found no correlation between SUS score and age which comes in line with the findings provided by Orfanou et al. (2015). A recent research (Mujinga et al., 2018) revealed a significant relation between age and SUS score $(r=0.036, \mathrm{p}=0.09, \mathrm{~s})$.

Thus, this literature review and meta-analysis has been guided by the following research questions:

RQ1. Which is the level of perceived usability of Learning Management Systems (LMS) and University websites in the context of higher education as it is reflected upon System Usability Scale (SUS)?

RQ2.Is there a significant difference in usability between the two types of technology?

RQ3. Which factors are related to SUS score (e.g. age, type and number of participants)?

RQ4.Is there a significant difference in usability at LMS and university websites over time?

\section{METHODOLOGY}

Firstly, this paper presents the findings of a systematic review of usability evaluation of LMS and University Websites used in higher education. The research was conducted after studying, organizing, and analyzing the results of 33 research papers evaluating the perceived usability of LMS and websites at university settings using the System Usability Scale (SUS). The methodology for this systematic review followed the guidelines proposed by Kitchenham (2004). Our search was conducted using the keywords at Google Scholar: sus, usability, learning management system or university website. The reported research papers were published from 2007 to 2019. The data were collected from October 2019 until January 2020. In the cases of inadequate or ambiguously reported data, we contacted the corresponding researchers.

Some inclusion and exclusion criteria were set at the beginning of the search. The inclusion criteria were a) Research papers which evaluate usability for LMS and university websites by using the SUS b) Research 
papers which were written in English. The exclusion criteria were: a) Research paper is not written in English, b) another scale or method was used for evaluating usability and c) the SUS scale is not used for educational purposes.

The results of the literature review were organized on a basis of (a) the usability rating as derived from the SUS questionnaire, (b) the type of educational technology (LMS or university website), (c) the number of participants in each sample, (d) the age and (g) the type of participants (e.g. teachers, students). The obtained data were analyzed with IBM SPSS Statistics v25.0. Possible correlations were investigated between independent variables and SUS score regarding the research questions. We have also taken into consideration possible variations at SUS score which may exist due to different sample sizes by reporting weighted means.

\section{RESULTS}

RQ1. Level of Perceived usability of LMS and University Websites

The Learning Management Systems (LMS) category comprised 40 studies and its mean SUS score was 66.88 ( $\mathrm{SD}=10.88$, see Table 1 ). The University websites category comprised 12 studies and its mean SUS score was 63.81 ( $\mathrm{SD}=16.51$, see Table 2). Possible variations in perceived usability score regarding the sample size of each survey were taken into consideration. Weighted SUS mean score for LMS is $(\mathrm{M}=60.14, \mathrm{SD}=15.02)$ and for university websites (M=65.83, $\mathrm{SD}=16.86)$. Considering the criteria set from Bangor et al. (2009), LMS and University websites seem to have good usability levels but with some design flaws.

Table 1. Overview of the studies included evaluating LMS

\begin{tabular}{|c|c|c|c|c|}
\hline Study & $\begin{array}{l}\text { Number of } \\
\text { participants }\end{array}$ & $\begin{array}{l}\text { Mean } \\
\text { SUS }\end{array}$ & $\begin{array}{c}\text { Mean } \\
\text { Age }\end{array}$ & $\begin{array}{c}\text { Participants (S: } \\
\text { Students/ T:Teachers, } \\
\text { U: Unknown) }\end{array}$ \\
\hline Pirker et al. (2019) & 14 & 70.63 & 23.43 & $\mathrm{~S}$ \\
\hline \multirow[t]{3}{*}{ Rosato et al. (2007) } & 13 & 59.00 & & $\mathrm{~S}$ \\
\hline & 13 & 64 & & $\mathrm{~S}$ \\
\hline & 16 & 72.50 & & $\mathrm{~S}$ \\
\hline Ivanović et al. (2018) & 96 & 74.70 & & $\mathrm{~S}$ \\
\hline Lehong et al. (2019) & 9 & 63 & & $\mathrm{~T}$ \\
\hline Erdoğmuş et al. (2015) & 10 & 50.75 & & $\mathrm{~S}$ \\
\hline \multirow[t]{3}{*}{ Katsanos et al. (2012) } & 45 & 74.50 & 21.04 & $\mathrm{~S}$ \\
\hline & 191 & 70.48 & 20.44 & $\mathrm{~S}$ \\
\hline & 44 & 71.48 & 37.2 & $\mathrm{~S}$ \\
\hline Rahimi et al. (2015) & 57 & 60.61 & 34.7 & $\mathrm{U}$ \\
\hline \multirow[t]{2}{*}{ Alshammari et al. (2016) } & 39 & 79.46 & \multirow{2}{*}{22.21} & $\mathrm{~S}$ \\
\hline & 36 & 71 & & $\mathrm{~S}$ \\
\hline Kaewsaiha (2019) & 41 & 56.83 & & $\mathrm{~T}$ \\
\hline \multirow{2}{*}{$\begin{array}{l}\text { Gutiérrez-Carreón et al. } \\
(2015)\end{array}$} & 24 & 83.3 & & $\mathrm{~S}$ \\
\hline & 32 & 76 & & $\mathrm{~S}$ \\
\hline $\begin{array}{l}\text { Srimarong \& Achalakul } \\
\text { (2017) }\end{array}$ & 9 & 57.22 & & $\mathrm{~T}$ \\
\hline Harrati et al. (2017) & 180 & 72.83 & 36.70 & $\mathrm{~T}$ \\
\hline Al-Sumaty \& Umar (2018) & 45 & 83.60 & & $\mathrm{~T}$ \\
\hline
\end{tabular}




\begin{tabular}{|c|c|c|c|c|}
\hline Binyamin et al. (2016) & 50 & 69.30 & & $\mathrm{~S}$ \\
\hline Erdoğan et al. (2017) & 204 & 67.14 & & $\mathrm{~S}$ \\
\hline García-Peñalvo et al. (2019) & 43 & 65.23 & 21 & $\mathrm{~S}$ \\
\hline \multirow[t]{3}{*}{ Tsironis et al. (2016) } & 31 & 66.30 & 31.5 & $\mathrm{~S}$ \\
\hline & 31 & 76.50 & 31.5 & $\mathrm{~S}$ \\
\hline & 31 & 65.90 & 31.5 & $\mathrm{~S}$ \\
\hline \multirow[t]{2}{*}{ Al-Omar (2018) } & 347 & 38 & & $\mathrm{~T}$ \\
\hline & 893 & 39 & & $\mathrm{~S}$ \\
\hline \multirow{2}{*}{ Blecken et al. (2010) } & 60 & 72 & & $\mathrm{~T}$ \\
\hline & 440 & 56 & & $\mathrm{~S}$ \\
\hline Vertesi et al. (2018) & 182 & 58.60 & & $\bar{U}$ \\
\hline Thuseethan et al. (2014) & 201 & 67.50 & & $\mathrm{~S}$ \\
\hline Harrati et al. (2016) & 50 & 69.30 & 37 & $\mathrm{~T}$ \\
\hline Orfanou et al. (2015) & 769 & 76.27 & 21.78 & $\mathrm{~S}$ \\
\hline Shi et al. (2013) & 10 & 75.75 & & $\mathrm{~S}$ \\
\hline Marco et al. (2013) & 10 & 89.50 & 23 & $\mathrm{~S}$ \\
\hline \multirow[t]{3}{*}{ Luo et al. (2014) } & 49 & 58.10 & & $\mathrm{~S}$ \\
\hline & 24 & 65.93 & & $\mathrm{~S}$ \\
\hline & 9 & 74.45 & & $\mathrm{~T}$ \\
\hline \multirow[t]{2}{*}{ Granić \& Ćukušić (2011) } & 47 & 59.36 & & $\mathrm{~S}$ \\
\hline & 23 & 53.15 & 40 & $\mathrm{~T}$ \\
\hline Total & 4418 & 66.88 & & \\
\hline
\end{tabular}

RQ2 comparison between LMS's and University Websites' SUS score

An independent samples t-test was conducted to investigate possible statistical differences between SUS score and the category of educational technology (LMS and university websites). No statistically significant difference was observed $(\mathrm{p}=0.454, \mathrm{~ns})$.

RQ3. Attributes which may relate to SUS score

In a dataset of 40 surveys of LMS' evaluation of perceived usability a moderate negative correlation between age and SUS score $(\mathrm{r}=-0.33, \mathrm{p}=0.05, \mathrm{~s})$ and between the number of participants and SUS score $(\mathrm{r}=-0.364, \mathrm{p}=0.021, \mathrm{~s})$ was found. It should be noted that in the study conducted by Alshammari et al. (2016) it is not completely clear if the mean age of the participants refers to the total number or for each group of the two reported studies. Thus, the second hypothesis was adopted and these two studies were not excluded from the analysis. For university websites, no data were provided for the variable age. Regarding the number of participants of the university websites' evaluation studies, no statistically significant correlation was found between SUS score and the number of participants $(r=0.347, p=0.269$, ns). 
Table 2. Overview of the studies included evaluating University Websites

\begin{tabular}{|c|c|c|c|}
\hline Study & $\begin{array}{l}\text { Number of } \\
\text { participants }\end{array}$ & $\begin{array}{l}\text { Mean } \\
\text { SUS }\end{array}$ & $\begin{array}{c}\text { Participants } \\
\text { (S: students, U: } \\
\text { Unknown) }\end{array}$ \\
\hline Alnasser et al. (2017) & 14 & 80.2 & $\mathrm{U}$ \\
\hline Demir \& Parraci (2018) & 6 & 68 & $\mathrm{~S}$ \\
\hline \multirow[t]{6}{*}{ Benaida et al. (2018) } & 20 & 91 & $\mathrm{~S}$ \\
\hline & 20 & 52.9 & $\mathrm{~S}$ \\
\hline & 20 & 90.8 & $\mathrm{~S}$ \\
\hline & 20 & 46.4 & $S$ \\
\hline & 20 & 73.4 & $\mathrm{~S}$ \\
\hline & 20 & 57.4 & $\mathrm{~S}$ \\
\hline \multirow[t]{2}{*}{ Sengel (2014) } & 10 & 43.75 & $\mathrm{U}$ \\
\hline & 10 & 54.38 & $\mathrm{U}$ \\
\hline Şengel (2013) & 8 & 54.06 & $\mathrm{~S}$ \\
\hline NaifJabli \& Demir (2018) & 10 & 53.5 & $\mathrm{~S}$ \\
\hline Total & 178 & 63.81 & \\
\hline
\end{tabular}

In addition, an independent samples t-test was conducted to investigate possible statistical differences between SUS score and the type of participant (student - teacher). There was no significant difference in the LMS context ( $\mathrm{p}=0.165, \mathrm{~ns})$. The sample referring to university websites' evaluation comprised students only.

\section{RQ4: Evolution of SUS ratings over time}

Perceived usability ratings over time were examined by using Repeated measures ANOVA. The years 2007, 2012 and 2019 were used as reference points for the LMS category ( $p=0.261$, ns) and 2014, 2018 for the University Websites category $(\mathrm{p}=0.128$, ns). Thus, a non-significant improvement was observed for both categories.

\section{CONCLUSIONS AND DISCUSSION}

The purpose of the research presented in this paper was to provide a summary of the findings regarding the perceived usability's evaluation of two core educational technologies used mainly in the context of higher education: LMS and University Websites. Their perceived usability was assessed using the System Usability Scale (SUS). It is argued that the significance of the reported research is significant by providing usability benchmarks for educational technology used in higher education to all stakeholders. As a result, those working in the field of Educational Technology will be knowledgeable at what levels the evaluation of systems varies. In addition, it will be proved useful for educational technology system designers as a basis for reporting and comparing results by raising the level of awareness of those involved.

Regarding the research questions, both LMS and University Websites seem to have a good usability level, but with some issues. It seems that in recent years special attention is given to the evaluation of the perceived usability of LMS but not to that of university websites. Perhaps this fact on the one hand implies a shift in distance asynchronous education, with emphasis on LMS as a complement to learning and on the other hand University websites may be neglected because they do not directly contribute to learning. Although LMS are considered "old technology", they are mainly used when users reach higher education stage. On the other side, the University websites do not aim directly at learning a particular subject, so they are a quite unrecognized dimension in the learning process. They are frequently a product of in-house development and their perceived 
usability may not be sufficiently taken into account as it is demonstrated by the research data. However, no significant difference was observed between the two categories concerning the usability ratings.

Furthermore, a strong negative correlation between age and SUS score was found for LMS ( $r=-0.533$, $\mathrm{p}=0.05)$. This is in line with the findings reported by Bangor et al. $2008(\mathrm{r}=-0.203, \mathrm{p}=0.03$, s) and Granić and Ćukušić (2011) ( $\mathrm{r}=-0.467, \mathrm{p}=0.001, \mathrm{~s})$, but contradicts the findings reported by Orfanou et al. $(2015, \mathrm{r}=-0.061$, $\mathrm{p}=0.09$ ) and Mujinga et al. (2018, $\mathrm{r}=0.036, \mathrm{p}=0.09$ ). For the university websites category, no data were provided for the "age" variable. In addition, the number of participants does not seem to affect SUS score for the University websites category. Nevertheless, a moderate negative correlation was found between the number of participants and SUS score at the LMS context $(\mathrm{r}=-0.364, \mathrm{p}=0.02, \mathrm{~s})$. This is a useful first record which needs further research to reach definitive and meaningful conclusions. Moreover, in LMS settings no statistically significant difference was observed $(\mathrm{p}=0.165, \mathrm{~ns})$ concerning the type of participant (student or teacher). In university websites category the studies consisted only of students. It is noteworthy that there is a slight non-statistically significant improvement at usability levels over time. This result is encouraging because the importance of usability is now more apparent and necessary than ever.

This research is not without limitations. Even though SUS is considered as a highly valid and reliable tool for evaluating the perceived usability (Orfanou et al., 2015), there is no universal consensus regarding the psychometric tool for evaluating usability. In addition, only the studies using System Usability Scale were included. Other usability parameters such as findability (Katsanos, Tselios \& Avouris, 2008) should be taken into consideration. Moreover, usability evaluation of websites was conducted by students. The results might be differentiated if other users such as prospective students, teachers or parents were taken into account. In addition, only 12 surveys were included at the usability's evaluation of university websites and most of them (7 out of 12) were carried out in 2018.

As for future research, it would be useful to conduct a study which will consider other stakeholders for evaluating the perceived usability of university websites such as alumni, prospective students and parents. In addition, it should be examined if there are any differentiations in the perceived usability depending on the academic discipline of the stakeholders involved (i.e. Humanities, Applied Sciences, Natural Sciences). For the LMS's, it would be useful to investigate possible relationships between SUS score and a) the learning object, b) the internet competency, c) the delivery method d) the information architecture of the LMS (Katsanos et al., 2008) and e) whether the participants are undergraduate or postgraduate students. Finally, the scope of the presented study can be expanded to take into account the perceived usability's evaluation of other types of educational technologies adopted in all educational stages.

\section{ACKNOWLEDGEMENT}

Part of the work presented in this paper has been completed in the context of the project: "ERMIS-F: Web services for environmental risk-Floods". Funding: Interreg V-A Greece - Cyprus.

\section{REFERENCES}

Alnasser, A., Alnabit, N., \& Alanazi, W. (2017). Usability Evaluation of Prototypes Designed for a Saudi University Website. International Journal of Computing \& Information Sciences, 13(1), 15-25.

Al-Omar, K. (2018). Evaluating the Usability and Learnability of the" Blackboard" LMS Using SUS and Data Mining. In Proceedings of the 2018 Second International Conference on Computing Methodologies and Communication (ICCMC), February 15-16, Erode, India, pp. 386-390. IEEE.

Alshammari, M., Anane, R., \& Hendley, R. J. (2016). Usability and effectiveness evaluation of adaptivity in e-learning systems. In Proceedings of the 2016 CHI conference extended abstracts on human factors in computing systems, May 7-12, San Jose, California, USA, pp. 2984-2991. ACM.

Al-Sumaty, R. M., \& Umar, I. N. (2018). Design and Evaluation of Cloud-Based Students Data Management System Usability. In Proceedings of the 2018 International Conference on Smart Computing and Electronic Enterprise (ICSCEE), July 11-12, Kuala Lumpur, Malaysia, pp. 1-8. IEEE.

Ardito, C., Costabile, M. F., De Marsico, M., Lanzilotti, R., Levialdi, S., Roselli, T., \& Rossano, V. (2006). An approach to usability evaluation of e-learning applications. Universal access in the information society, 4(3), 270-283. 
Bangor, A., Kortum, P. T., \& Miller, J. T. (2008). An empirical evaluation of the system usability scale. Intl. Journal of Human-Computer Interaction, 24(6), 574-594.

Bangor, A., Kortum, P., \& Miller, J. (2009). Determining what individual SUS scores mean: Adding an adjective rating scale. Journal of usability studies, 4(3), 114-123.

Benaida, M., Namoun, A., \& Taleb, A. (2018). Evaluation of the Impact of Usability in Arabic University Websites: Comparison between Saudi Arabia and the UK. Evaluation, 9(8), 365-375.

Binyamin, S., Rutter, M., \& Smith, S. (2016). The utilization of system usability scale in learning management systems: A case study of Jeddah Community College. In Proceedings of the 9th International Conference of Education, Research and Innovation (ICERI2016), November 14-16, Seville, Spain, pp. 5314-5323, International Academy of Technology, Education and Development (IATED).

Blecken, A., Bruggemann, D., \& Marx, W. (2010). Usability evaluation of a learning management system. In Proceedings of the 2010 43rd Hawaii International Conference on System Sciences, January 5-8, Honolulu, Hawaii, USA, pp. 1-9. IEEE.

Brooke, J. (1996). SUS-A quick and dirty usability scale. Usability evaluation in industry, 189(194), 4-7.

Coates, H., James, R., \& Baldwin, G. (2005). A Critical Examination of the Effects of Learning Management Systems on University Teaching and Learning. Tertiary Education and Management, 11(1), 19-36.

Demir, F., \& Parraci, W. (2018). The more complex the less success in online library services: Evaluating the user experience for international students. Issues and Trends in Educational Technology, 6(2), 50-64.

Erdoğan, T., Yıldırım, O. G., \& Çiğdem, H. (2017). The Investigation of the Usability of Web-Based Assignment System. Journal of Theory and Practice in Education, 13(1), 1-9.

Erdoğmuş, F., Kokoç, M., Pinal, E., Bilgi, Ş., \& Murat, Z. (2015). Investigation of an Online Learning Environment in Terms of Usability. Participatory Educational Research, 2(3), 55-66.

García-Peñalvo, F. J., Vázquez-Ingelmo, A., García-Holgado, A., \& Seoane-Pardo, A. M. (2019). Analyzing the usability of the WYRED Platform with undergraduate students to improve its features. Universal Access in the Information Society, 18(3), 455-468.

Georgsson, M., \& Staggers, N. (2016). Quantifying usability: an evaluation of a diabetes mHealth system on effectiveness, efficiency, and satisfaction metrics with associated user characteristics. Journal of the American Medical Informatics Association, 23(1), 5-11.

Granić, A., \& Ćukušić, M. (2011). Usability testing and expert inspections complemented by educational evaluation: A case study of an e-learning platform. Journal of Educational Technology \& Society, 14(2), 107-123.

Gutiérrez-Carreón, G., Daradoumis, T., \& Jorba, J. (2015). Integrating learning services in the cloud: An approach that benefits both systems and learning. Journal of Educational Technology \& Society, 18(1), 145-157.

Harrati, N., Bouchrika, I., \& Mahfouf, Z. (2017). Investigating the uptake of educational systems by academics using the technology to performance chain model. Library Hi Tech, 35(4), 629-648.

Harrati, N., Bouchrika, I., Tari, A., \& Ladjailia, A. (2016). Exploring user satisfaction for e-learning systems via usage-based metrics and system usability scale analysis. Computers in Human Behavior, 100(61), 463-471.

Ituma, A. (2011). An evaluation of students' perceptions and engagement with e-learning components in a campus-based university. Active Learning in Higher Education, 12(1), 57-68.

Ivanović, M., Milicević, A. K., Ganzha, M., Bădică, A., Paprzycki, M., \& Bădică, C. (2018, January). Usability and Quality Parameters for E-Learning Environments and Systems. In CEUR Workshop Proceedings.

Kaewsaiha, P. (2019). Usability of the Learning Management System and Choices of Alternative. In Proceedings of the 2019 International Conference on Education, Psychology, and Social Sciences (ICEPS), August 22-24 Tokyo, Japan, pp. 252-259.

Katsanos C., Tselios N., \& Avouris N. (2008). AutoCardSorter: Designing the Information Architecture of a Web Site using Latent Semantic Analysis. In Proceedings of the SIGCHI conference on Human factors in computing systems, CHI 2008, Florence, Italy, pp. 875-878. ACM Press.

Katsanos, C., Tselios, N., \& Xenos, M. (2012). Perceived usability evaluation of learning management systems: a first step towards standardization of the System Usability Scale in Greek. In Proceedings of the 2012 16th Panhellenic Conference on Informatics, Piraeus, Greece, pp. 302-307. IEEE.

Kitchenham, B. (2004). Procedures for performing systematic reviews. Keele, UK, Keele University, 33(2004), 1-26.

Lehong, S., van Biljon, J., \& Sanders, I. (2019). Open-distance electronic learning environments: Supervisors' views on usability. In Proceedings of the 2019 Conference on Information Communications Technology and Society (ICTAS), March 6, Durban, Africa, pp. 1-7. IEEE.

Lewis, J. R. (1991). An after-scenario questionnaire for usability studies: psychometric evaluation over three trials. ACM SIGCHI Bulletin, 23(4), 79. 
Lewis, J. R. (1992). Psychometric evaluation of the post-study system usability questionnaire: The PSSUQ. In Proceedings of the Human Factors and Ergonomics Society Annual Meeting, October 1, Santa Mónica, California, USA, pp. 1259-1263, Human Factors Society

Lewis, J. R. (1995). IBM computer usability satisfaction questionnaires: psychometric evaluation and instructions for use. International Journal of Human-Computer Interaction, 7(1), 57-78.

Luo, G. H., Liu, E. Z. F., Kuo, H. W., \& Yuan, S. M. (2014). Design and implementation of a simulation-based learning system for international trade. International Review of Research in Open and Distributed Learning, 15(1), 203-226.

Marco, F. A., Penichet, V. M. R., \& Gallud, J. A. (2013). Collaborative e-Learning through Drag \& Share in Synchronous Shared Workspaces. J. UCS, 19(7), 894-911.

McCann, D, Christmass, J, Nicholson, P \& Stuparich, J (1998). Educational technology in higher education. Occasional papers series (Australia. Department of Employment, Education and Training. Higher Education Division), DEETYA, Canberra.

Mentes, S. A., \& Turan, A. H. (2012). Assessing the usability of university websites: An empirical study on Namik Kemal University. Turkish Online Journal of Educational Technology-TOJET, 11(3), 61-69.

Mujinga, M., Eloff, M. M., \& Kroeze, J. H. (2018). System usability scale evaluation of online banking services: A South African study. South African Journal of Science, 114(3-4), 1-8.

NaifJabli, H., \& Demir, F. (2018) The Usability of King Khalid University Website: Assessing Effectiveness, Efficiency, And Satisfaction. International Journal of Arts Humanities and Social Sciences, 3 (7), 10-16.

Orfanou, K., Tselios, N., \& Katsanos, C. (2015). Perceived usability evaluation of learning management systems: Empirical evaluation of the System Usability Scale. International Review of Research in Open and Distributed Learning, 16(2), 227-246.

Pirker, J., Holly, M., Almer, H., Gütl, C., \& Belcher, J. W. (2019). Virtual Reality STEM Education from a Teacher's Perspective. In Proceedings of the Immersive Learning Research Network Conference (iLRN), June 23-27, London, UK.

Rahimi, A., Embi, M. A., \& Rahimi, A. (2015). Evaluation of the e-Learning developed for casemix and clinical coding: Quality of the material and usability of the system. Argos Special Issue 2, 130-143.

Rosato, J., Dodds, C., \& Laughlin, S. (2007). Usability of course management systems by students. Dept. Computer Information Systems/Computer Science, College of Scholastica, Duluth.

Şengel, E. (2013). Usability level of a university web site. Procedia-Social and Behavioral Sciences, 106, 3246-3252.

Sengel, E. (2014). Discovering How Students Search a University Web Site: A Comparative Usability Case Study for PC and Mobile Devices. Turkish Online Journal of Educational Technology-TOJET, 13(4), 12-20.

Shi, L., Awan, M. S. K., \& Cristea, A. I. (2013). Evaluating system functionality in social personalized adaptive e-learning systems. In Proceedings of the European Conference on Technology Enhanced Learning, September 17-21, Paphos, Cyprus, pp. 633-634. Springer.

Smith, J., \& Oliver, M. (2000). Academic development: A framework for embedding learning technology. International Journal for Academic Development, 5(2), 129-137.

Srimarong, S., \& Achalakul, T. (2017). Usability evaluation of outcome-based education tool. In Proceedings of the 2017 IEEE 9th International Conference on Engineering Education (ICEED), November 9-10, Kanazawa, Japan, pp. 233-237. IEEE.

Thuseethan, S., Achchuthan, S., \& Kuhanesan, S. (2014). Usability evaluation of learning management systems in Sri Lankan universities. arXiv preprint arXiv:1412.0197.

Tsironis, A., Katsanos, C., \& Xenos, M. (2016, April). Comparative usability evaluation of three popular MOOC platforms. In Proceedings of the 2016 IEEE Global Engineering Education Conference (EDUCON), April 10-13, Abu Dhabi, UAE, pp. 608-612. IEEE.

Tullis, T., \& Albert, B. (2008). Measuring the user experience: Collecting. Analyzing, and Presenting Usability Metrics, 124.

Vertesi, A., Dogan, H., Stefanidis, A., Ashton, G., \& Drake, W. (2018). Usability Evaluation of a Virtual Learning Environment: a University Case Study. In Proceedings of the 15th International Conference on Cognition and Exploratory Learning in Digital Age (CELDA), October 21-23, Budapest, Hungary, IADIS. 